Gut, 1989, 30, 54-59

\title{
Postprandial antral hypomotility in patients with idiopathic nausea and vomiting
}

\author{
PAUL KERLIN
}

From the Department of Gastroenterology, Princess Alexandra Hospital, Brisbane, Queensland, Australia

SUMmary The pathogenesis of idiopathic nausea and vomiting is poorly understood and could involve disorders of gut motility. The contractile activity of the stomach and small bowel was studied in 20 patients (seven men) with nausea and vomiting for longer than six months. None had previous gastric surgery, mechanical obstruction and metabolic causes were excluded. Fasting (four hours) and fed (up to two hours) contractile activity was recorded by a low compliance infusion system from the gastric antrum (four sites), the duodenum and the jejunum. Normal criteria were established in seven healthy controls. During fasting, from one to three (median 2) migrating motor complexes (MMC's) were present in patients and controls. Only two patients had contractile abnormalities during fasting. After a solid-liquid test meal, the contractility of the gastric antrum (quantified electronically as a cumulative motility index for 60 minutes) was significantly impaired in patients $(p=0.012)$. Six patients had normal qualitative and quantitative antral activity but two of them had 'phase III-like fasting activity' in the small bowel after the test meal. Postprandial antral hypomotility was identified as a major abnormality in patients with unexplained nausea and vomiting.

The symptoms of nausea and vomiting may be secondary to gastric outlet obstruction, previous gastric surgery, neuromuscular disorders or metabolic disturbances such as diabetes mellitus.' The symptoms may also occur in the absence of a recognised cause. One approach to investigate patients with unexplained nausea and vomiting has been electrogastrography by external (cutaneous) or internal (intragastric) suction electrodes. The intrinsic rhythmical myoelectrical activity of the stomach (the 'slow wave' or electrical control activity) occurs at a frequency of $0.05 \mathrm{~Hz}$. Contractions are associated with rapid changes in potential (spike bursts) superimposed on the slow waves. Abnormal myoelectrical activity, including tachygastria (electrical control activity at a higher rate than normal) was first reported in an infant with vomiting and gastric retention. ${ }^{2}$ You et $a l^{3}$ noted disorganisation of

Address for correspondence: Paul Kerlin, MD, FRACP, Gastroenterology Department, Princess Alexandra Hospital, Ipswich Road, Brisbane, Queensland 4102, Australia.

Received for publication 21 July 1988. the gastric myoelectrical activity during fasting in patients with nausea and vomiting. More recently, Geldof and colleagues ${ }^{4}$ described frequency variations mainly in the postprandial phase. Many of the patients studied by Geldof's group with unexplained nausea and vomiting had delayed gastric emptying. Although myoelectrical activity is the basis of gastric contractile activity, the motor counterpart of these observations had not been clarified.

In health, gastrointestinal motility during fasting is characterised by the migrating motor complex (MMC) which migrates distally from stomach through the small bowel about every 90 minutes. $^{56}$ With ingestion of a solid-liquid meal these cyclic motor events are interrupted and replaced in the stomach by a marked increase in antral contractions which serve to grind the solid food to tiny particles about $1 \mathrm{~mm}$ in size before being emptied into the duodenum. ${ }^{7}$ In diabetics with gastroparesis, gastric interdigestive motor complexes are absent and there is reduced postprandial gastric motor activity." Malagelada and Stanghellini ${ }^{9}$ have recently described 
manometric abnormalities in a mixed group of patients, including diabetics and patients with functional upper gut symptoms.

The aim of this study was to evaluate the gastrointestinal contractile activity in a group of patients with chronic, unexplained nausea and vomiting after exclusion of known predisposing conditions.

\section{Methods}

PATIENTS AND HEALTHY CONTROLS

Twenty consecutive patients (seven men, 13 women, aged 22-64 years, mean 35) referred for investigation of chronic, unexplained nausea and vomiting, participated in these studies. The research protocol was approved by the Princess Alexandra Hospital Ethics Committee and each patient and control gave written informed consent. The entry requirements for the study were the presence of chronic $(>6$ months) nausea and vomiting without known cause. Exclusion criteria were: (a) previous gastric surgery; (b) mechanical obstruction or significant mucosal pathology of the upper gastrointestinal tract; (c) diabetes mellitus, and (d) known neurological or myopathic disorders. The diagnostic workup of the patients included a barium meal examination, upper gastrointestinal endoscopy, a blood count and biochemistry including electrolytes, renal function and liver function tests. Results of these tests were normal except for the radiological findings of a large, atonic stomach in one patient. Later during the study the workup schedule was modified to include prepyloric endoscopic biopsies to check for the presence of Campylobacter pylori. ${ }^{10}$ Patients with abdominal pain (14) had an ultrasound examination to exclude cholelithiasis. Eleven patients had a small bowel biopsy carried out. The intestinal morphology and the disaccharidase determinations were normal in these subjects.

The spectrum of symptoms in the 20 patients is shown in the Table. Nausea and vomiting had been present for six months to 20 years (median duration 18 months). Symptoms followed a viral illness with pericarditis in a woman of 39 years. No precipitating event was apparent in the remainder. Vomiting usually followed within several hours of a meal, particularly a large meal. Vomiting usually relieved the nausea. Five $(25 \%)$ patients described the presence in morning vomitus of food eaten the previous evening. Several patients reported minor haematemeses after vomiting. The frequency of the associated symptoms of early satiety and a sensation of abdominal bloating is also illustrated in the Table. Significant ( $>10 \%$ weight) weight loss occurred in five patients. Symptoms tended to be cyclical, with exacerbations and remissions. There was no apparent relationship of symptom severity to the menstrual cycle or the use of oral contraceptives.

Table Clinical details of patients with idiopathic nausea and vomiting

\begin{tabular}{|c|c|c|c|c|c|c|c|c|c|c|c|}
\hline & & & & \multicolumn{7}{|c|}{ Symptoms } & \multirow[b]{2}{*}{$\begin{array}{l}\text { Campylobacter } \\
\text { pylori }\end{array}$} \\
\hline & & & & Nausea & Vomiting & $\begin{array}{l}\text { Early } \\
\text { satiety }\end{array}$ & Bloating & $\begin{array}{l}\text { Pain/ } \\
\text { discomfort }\end{array}$ & $\begin{array}{l}\text { Weight } \\
\text { loss }\end{array}$ & $\begin{array}{l}\text { Diarrhoeal } \\
\text { constipation }\end{array}$ & \\
\hline MC & 18 & $\mathbf{F}$ & 24 & + & + & + & + & + & - & - & ND \\
\hline JN & 29 & $\mathbf{M}$ & 6 & + & + & + & + & - & $4 \mathrm{~kg}$ & - & ND \\
\hline PF & 19 & $\mathbf{M}$ & 24 & + & + & - & - & + & - & - & ND \\
\hline SB & 20 & $F$ & life long & + & + & - & + & + & $2 \mathrm{~kg}$ & - & ND \\
\hline JD & 34 & $F$ & 8 & + & + & - & - & - & - & - & ND \\
\hline DB & 22 & $\mathbf{M}$ & 8 & + & + & + & + & + & $8 \mathrm{~kg}$ & $\mathrm{D} / \mathrm{C}$ & ND \\
\hline SJ & 29 & $\mathbf{F}$ & 96 & + & + & - & - & - & $7 \mathrm{~kg}$ & C & ND \\
\hline GC & 43 & $\mathbf{M}$ & 9 & ++ & ++ & + & + & ++ & $5 \mathrm{~kg}$ & $\mathrm{D}$ & - \\
\hline $\mathrm{CC}$ & 49 & $\mathbf{M}$ & 36 & +++ & ++ & ++ & +++ & + & $11 \mathrm{~kg}$ & $\mathrm{C}$ & + \\
\hline FJ & 43 & $\mathbf{M}$ & 18 & + & + & + & + & - & - & - & + \\
\hline AH & 39 & $F$ & 18 & ++ & ++ & ++ & ++ & + & 9 kg & - & - \\
\hline WS & 24 & $F$ & 12 & ++ & +++ & ++ & +++ & $+t+$ & $3 \mathrm{~kg}$ & $\mathrm{C}$ & - \\
\hline KM & 50 & $\mathbf{M}$ & 12 & +++ & +++ & ++ & - & + & $4 \mathrm{~kg}$ & - & + \\
\hline SS & 35 & $F$ & 12 & +++ & ++ & $++t$ & ++ & ++ & - & - & + \\
\hline LP & 36 & $\mathbf{F}$ & 18 & ++ & ++ & +++ & +++ & ++ & - & D & - \\
\hline LT & 43 & $\mathbf{F}$ & 39 & +++ & + & ++ & +++ & ++ & - & - & + \\
\hline GB & 50 & $\mathbf{F}$ & 36 & ++ & ++ & + & + & + & - & - & + \\
\hline JB & 26 & $\mathbf{F}$ & 24 & +++ & ++ & +++ & ++ & - & - & - & - \\
\hline DG & 64 & $\mathbf{F}$ & 22 & ++ & ++ & ++ & ++ & +++ & - & $\mathrm{C}$ & + \\
\hline KD & 29 & $\mathbf{F}$ & 48 & +++ & + & + & ++ & + & $3 \mathrm{~kg}$ & $\mathrm{C}$ & - \\
\hline
\end{tabular}

Scoring: - absent,+ mild,++ moderate,+++ severe.

Diarrhoea defined as more than three stools daily, constipation defined as fewer than three stools weekly. The presence of Campylobacter pylori was determined by examination of prepyloric endoscopic biopsies prepared with the Warthin-Starry stain. ND: not done. 


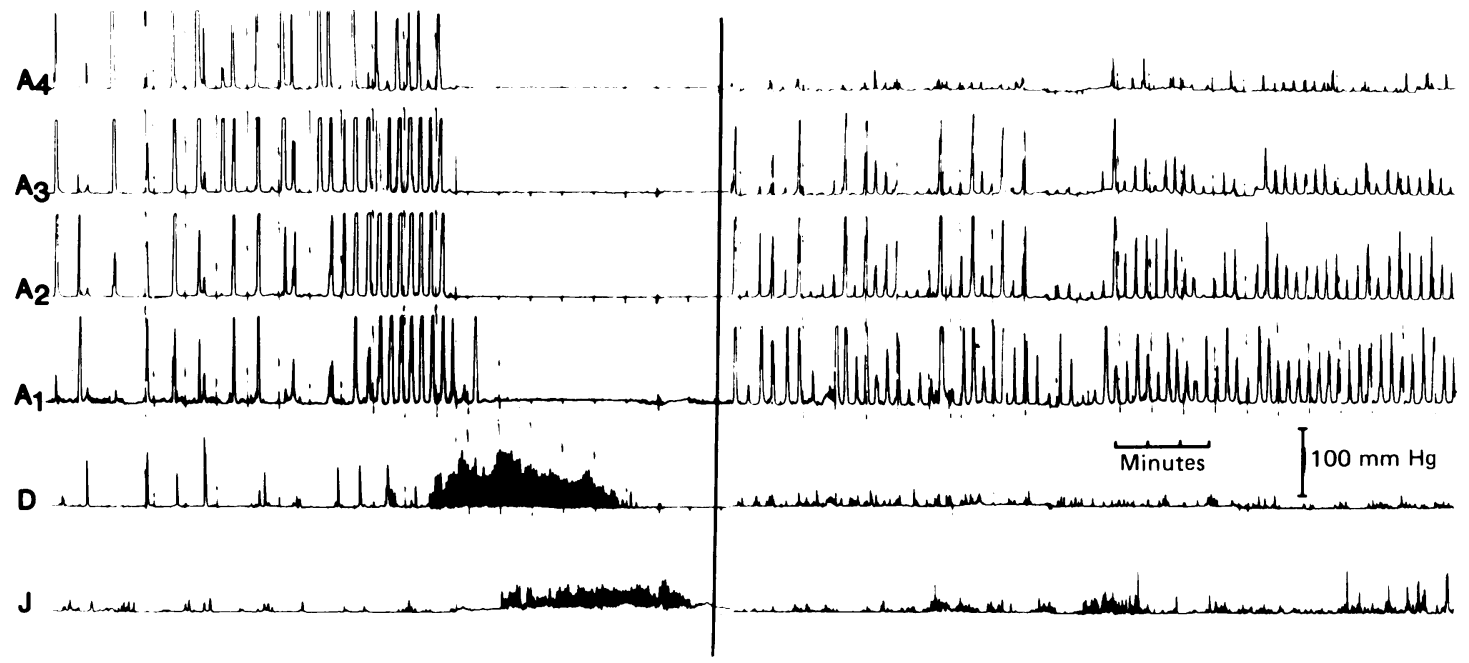

Fig. 1 Gastrointestinal contractile activity in a healthy control subject. Recordings are from the gastric antrum (A4 to Al at $1 \mathrm{~cm}$ intervals), the duodenum $(D)$ and the jejunum $(J)$. The left panel shows a migrating motor complex during fasting. The right panel shows postprandial activity. The fed state is characterised by high amplitude regular contractions (three/min).

INTESTINAL INTUBATION

Subjects were intubated by mouth with a multilumen tube (od $4 \cdot 1 \mathrm{~mm})$ after a 12 hour fast. Patients had not received medications likely to affect gut motility for seven days before the study. Under fluoroscopic guidance recording loci were positioned in the gastric antrum (four sites, $1 \mathrm{~cm}$ apart), in the second part of the duodenum and in the proximal jejunum. Passage of the tube beyond the pylorus was facilitated by the use of a small balloon at the "lead point' of the tube." Pressures were recorded by a low compliance infusion system (flow rate $0.5 \mathrm{ml} / \mathrm{min}$ ) validated previously." The system featured an electronic integrator which allowed simultaneous recording of

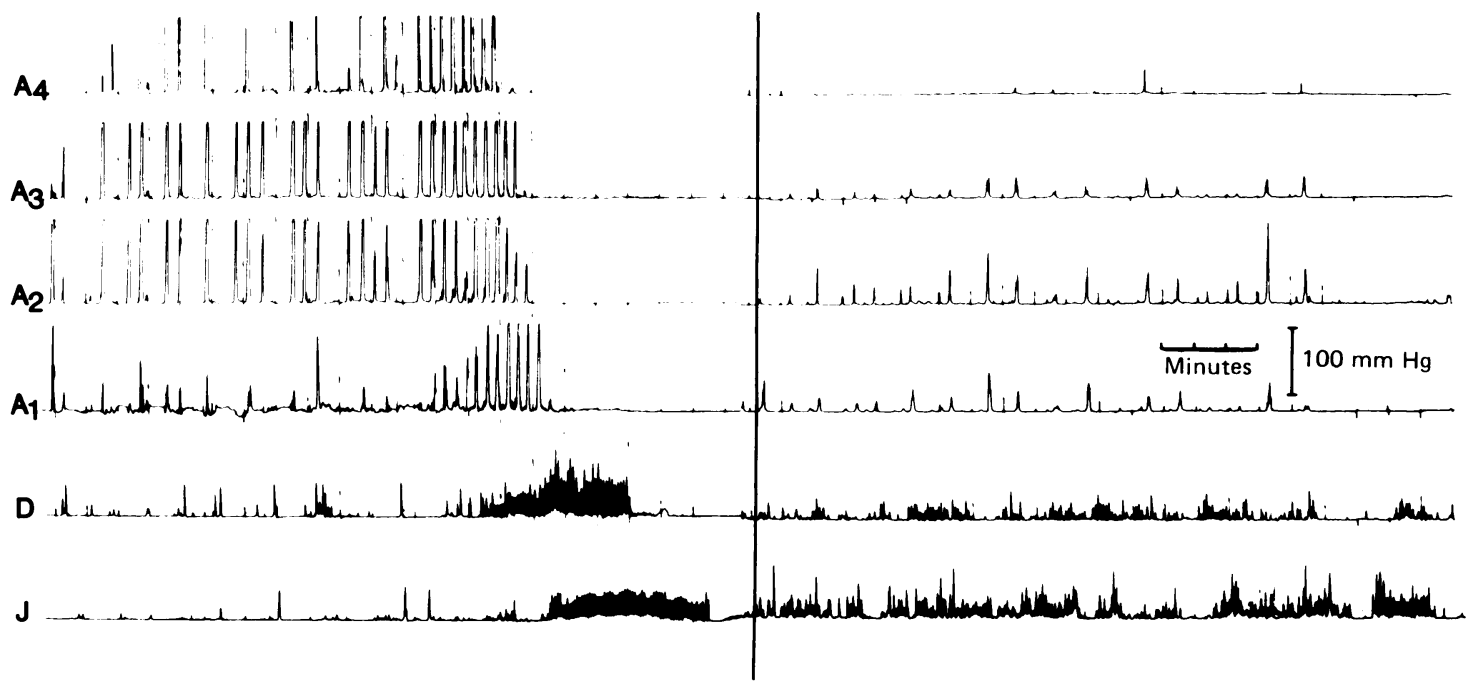

Fig. 2 Gastrointestinal contractile activity in a patient with unexplained nausea and vomiting. Recordings are from the gastric antrum ( $A 4$ to Al at $1 \mathrm{~cm}$ intervals), the duodenum $(D)$ and the jejunum $(J)$. Motility during fasting (left panel) is normal with a migrating motor complex. The right panel shows postprandial activity. The gastric antrum is quiescent with infrequent low amplitude contractions. 
the motility index ('area under the curve') each minute from each gastric recording site. ${ }^{12}$

\section{EXPERIMENTAL PROTOCOL}

Motor recordings were made for four hours in the fasting state. Subjects then received a test meal of ground beef steak $(120 \mathrm{~g})$ and boiled rice $(25 \mathrm{~g})$. This test meal provided $216 \mathrm{kcal}$ with a distribution of nutrients of protein $52 \%$, carbohydrate $40 \%$, and fat $8 \%$. After the test meal contractile activity was monitored for at least $1.75 \mathrm{~h}$. At the conclusion of the study the position of the tube was verified by fluoroscopy.

\section{MOTILITY ANALYSIS}

\section{Descriptive data (visual assessment of recordings)}

The MMC was identified on visual inspection of the recordings by the presence of phase III (the activity front) of the migrating motor complex (MMC). This required an uninterrupted series of contractions in the intestine lasting more than three minutes, followed by quiescence. ${ }^{6}$ Gastric phase III was considered to be present if regular activity (three/min) for at least one minute was followed by a duodenal phase III. The number of intestinal complexes preceded by gastric phase III was recorded. Postprandial records were scrutinised similarly to seek any recurrent patterns of motor activity.

\section{Quantitative data (integrated motility index)}

The cumulative integrated gastric motility index for the first hour after the meal was compared in patients and controls. For each individual the most active antral site was chosen for the comparison. Pyloric activity (tonic rise in baseline pressure with superimposed contractions) was occasionally noted and was not included in the quantitative analysis. Normal antral contractility after a meal was defined as a cumulative integrated motility index greater than the minimum value measured in the healthy controls. ${ }^{9}$

\section{Statistical analysis}

Results are expressed as the median and range. Because of possible non-parametric distribution of data, results were analysed by the Wilcoxon's ranksum test for unpaired data.

\section{Results}

DESCRIPTIVE ASPECTS: FASTING AND AFTER FOOD

Migrating motor complexes were present during fasting in all patients and controls. The number of complexes per individual (1-3; median 2) was similar between the groups. Migrating motor complexes were always antegrade and there was no difference in the duration of phase III or the maximal contractile frequency (median: three/min) in the antrum. Gastric phase III activity preceded intestinal complexes in 23 of $33(69.7 \%)$ MMC's in patients and in 10 of $16(62.5 \%)$ MMC's observed in the controls (Figs 1 and 2). During intestinal phase III the duodenal contraction rate in patients was $10 \cdot 3-12 \cdot 6$ /

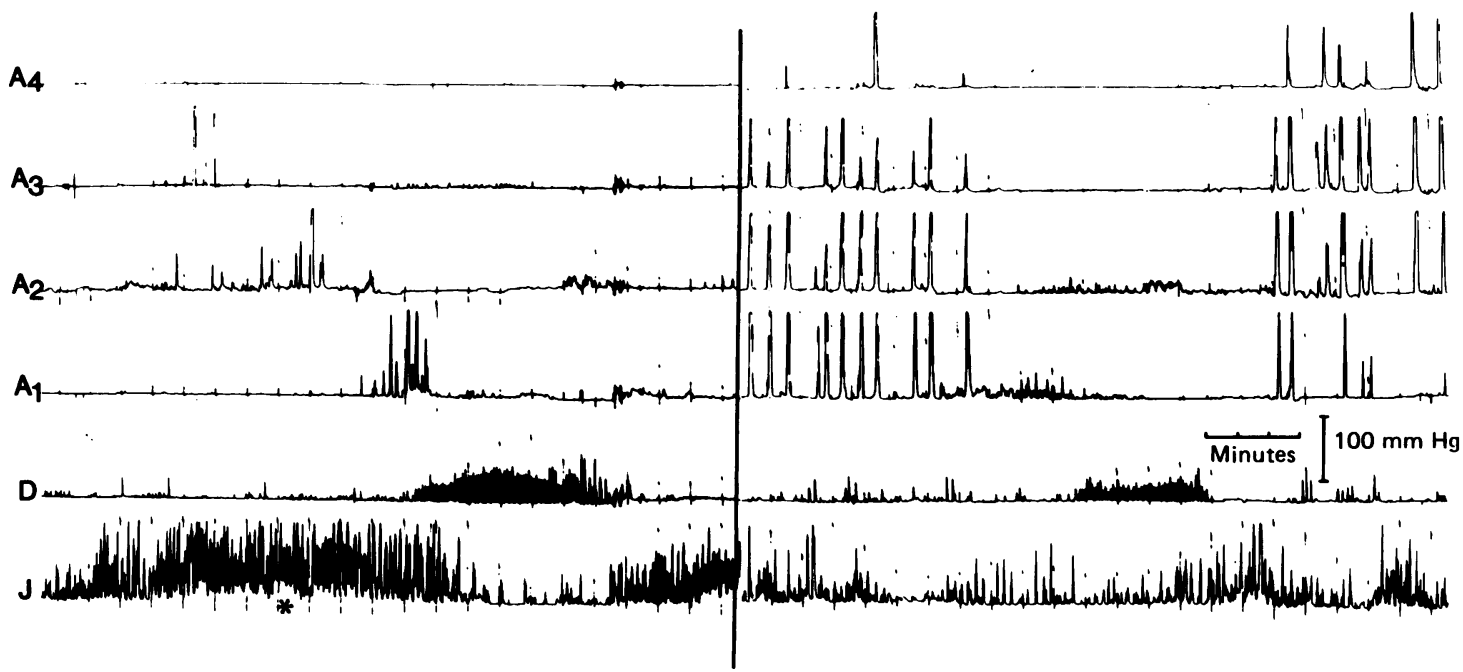

Fig. 3 Gastrointestinal contractile activity in a patient with unexplained nausea and vomiting. Recordings are from the gastric antrum (A4 to $A 1$ at $1 \mathrm{~cm}$ intervals), the duodenum $(D)$ and the jejunum $(J)$. The left panel demonstrates a burst $(*)$ of phasic activity with a tonic element of $10-20 \mathrm{mmHg}$ and a normal duodenal phase III of the MMC. The right panel of postprandial contractility demonstrates phase III like activity in the duodenum with interruption of antral phase activity. 
min (median 11.6) and the jejunal contraction rate $10 \cdot 3-12.0 /$ min (median 10.5). These rates were not different from values in controls. Two patients and one control had only intestinal complexes without a gastric component.

Probable abnormalities during fasting were confined to patients $\mathrm{KM}$ and $\mathrm{KD}$. In patient $\mathrm{KM}$, the motility tracing showed continual contractions in the antrum at a frequency of three/min for periods of 65 minutes and 30 minutes respectively. After the test meal, this patient also showed antral motor quiescence (see below). Patient KD, a woman aged 29 years, had a variety of abnormalities. High pressure phasic contractions with a tonic element were noted in the jejunum during fasting and a phase III-like burst appeared in the duodenum 35 minutes after the meal. The burst was associated with temporary quiescence of gastric contractions (Fig. 3).

The major abnormalities in patients with recurrent nausea and vomiting were noted after the test meal. In patients the activity of the gastric antrum was markedly reduced compared with the controls $(p=$ 0.012) (Fig. 2 and Fig. 4). Six patients had qualitatively and quantitatively normal antral motility but two of these subjects (DB, KD) had phase III-like activity in the small bowel after the meal (Fig. 3).

\section{Discussion}

The patient with unexplained chronic nausea, vomiting, and abdominal pain/discomfort presents a frustrating clinical problem. The current studies were designed to elucidate possible gastric contractile abnormalities in a consecutive group of patients with prolonged symptoms. In diabetics with similar symptoms and gastroparesis the antral component of the $\mathrm{MMC}$ is characteristically lacking ${ }^{8}$ although abnormalities of small bowel motility have also been recognised. ${ }^{13}$ In contrast, fasting gastric and small bowel contractility was considered normal in the majority of the current patients. All interdigestive motor complexes were antegrade and there was no evidence of antral phasic activity in patients at a rate which exceeded the frequency of contractions in the controls. The major abnormality identified in this and a previous study ${ }^{9}$ was reduced antral phasic contractility after the test meal. In the study of Malagelada and Stanghellini, $75 \%$ of patients with severe functional symptoms had impaired postprandial antral motor activity. ' Whether myoelectrical abnormalities underlie the postprandial hypomotility cannot be determined on available data.

The likely outcome of reduced mechanical trituration of solids by the gastric antrum is delayed gastric emptying of solids. Indeed, there is a positive correla-

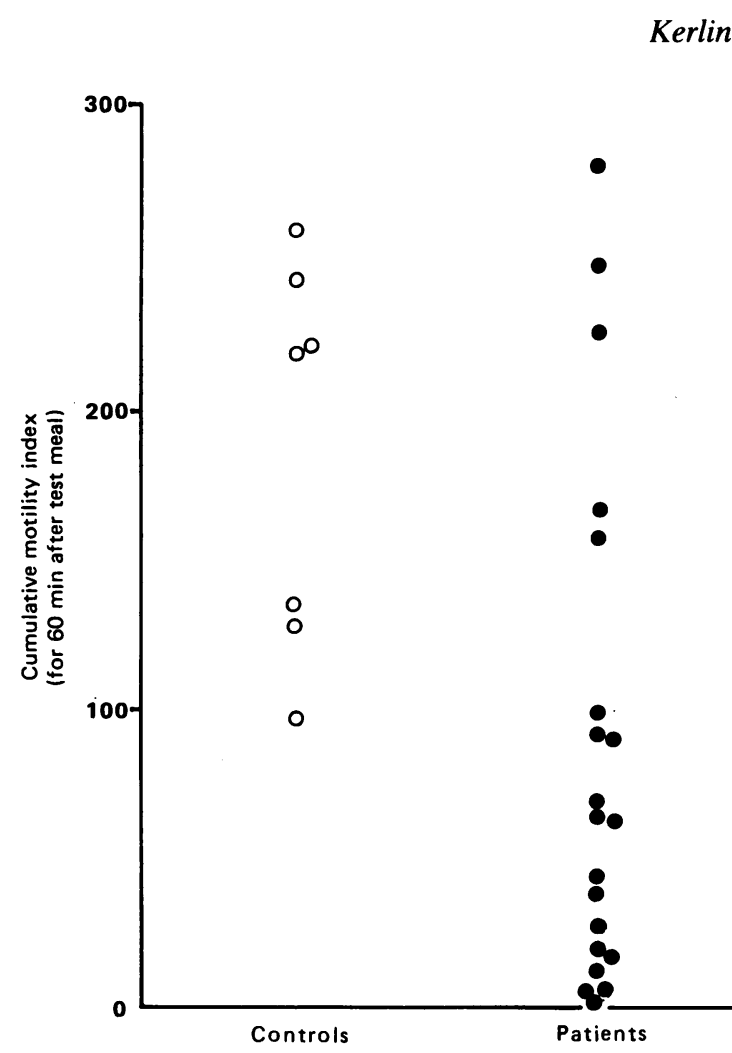

Fig. 4 The cumulative motility index (electronic integrator) for 60 minutes after the test meal for healthy controls and the patients with idiopathic nausea and vomiting.

tion between postcibal contractile activity, measured manometrically, and the rate of emptying of a radiolabelled meal, measured radioscintigraphically. ${ }^{14}$ Further, Jian et al reported delayed gastric emptying of radiolabelled solids in $44 \%$ of a series of patients with idiopathic dyspepsia. ${ }^{15}$

Postprandial antral hypomotility may be a final common pathway in several clinical states characterised by nausea and vomiting. Antral hypomotility and/or delayed gastric emptying have been reported in heterogeneous states including diabetes mellitus, ${ }^{8}$ after vagotomy,${ }^{8}$ in anorexia nervosa,${ }^{16}$ reflux oesophagitis, ${ }^{17}$ progressive systemic sclerosis, ${ }^{18}$ myotonic dystrophy, ${ }^{19}$ intestinal pseudoobstruction, ${ }^{20}$ after fundoplication, ${ }^{21}$ and even in healthy individuals in stressful situations. Acute experimental stress in the laboratory has been shown to reduce antral phasic activity and delay gastric emptying. ${ }^{22}{ }^{23}$ Whether impaired antral motility has a primary role in the pathogenesis of symptoms in these diseases or occurs secondary to them has not been determined.

The significance of infection with Campylobacter pylori in seven of $13(54 \%)$ patients sampled is uncertain. Campylobacter pylori and the associated 
non-autoimmune active gastritis have been proposed as a possible cause of non-ulcer dyspepsia. These bacteria are present in prepyloric biopsies from $24 \%$ of healthy controls and from $64 \%$ of patients with non-ulcer dyspepsia. ${ }^{24}$ In a preliminary report the gastric emptying of solids by patients with 'dyspepsia' and gastritis with Campylobacter, however, did not differ from results in healthy controls. ${ }^{25}$

In summary, $70 \%$ of a consecutive series of patients with idiopathic nausea and vomiting had impaired antral contractility after a test meal. The abnormality is not specific for this group of patients but also occurs in a heterogeneous group of patients with diverse disease processes.

This work was supported by a project grant from the National Health and Medical Research Council of Australia. The author thanks Beverly Harris for technical assistance and Valerie Millar for manuscript preparation.

\section{References}

1 Malagelada JR, Camilleri M. Unexplained vomiting: a diagnostic challenge. Ann Intern Med 1984; 101: 211-8.

2 Telander RL, Morgan KG, Kreulen DL, Schmalz PF, Kelly KA, Szurszewski JH. Human gastric atony with tachygastria and gastric retention. Gastroenterology 1978; 75: 497-501.

3 You CH, Lee KY, Chey WY, Menguy R. Electrogastrographic study of patients with unexplained nausea, bloating and vomiting. Gastroenterology 1980; 79: $311-4$

4 Geldof $H$, Vanderschee EJ, Vanblankenstein $M$, Grashuis JL. Electrogastrographic study of gastric myoelectrical activity in patients with unexplained nausea and vomiting. Gut 1986; 27: 799-808.

5 Rees WDW, Go VLW, Malagelada J-R. Antroduodenal motor response to solid-liquid and homogenised meals. Gastroenterology 1979; 76: 1438-42.

6 Kerlin P, Phillips SF. Variability of motility of the ileum and jejunum in healthy man. Gastroenterology 1982; 82: 694-700.

7 Meyer JH, Ohashi H, Jehu D, Thompson JB. Size of liver particles emptied from the human stomach. Gastroenterology 1981; 80: 1489-96.

8 Malagelada J-R, Rees WDW, Mazzotta LJ, Go VLW. Gastric motor abnormalities in diabetic and postvagotomy gastroparesis: effect of metoclopramide and bethanecol. Gastroenterology 1980; 78: 286-93.

9 Malagelada J-R, Stanghellini V. Manometric evaluation of functional upper gut symptoms. Gastroenterology 1985; 88: 1223-31.
10 Marshall B. Unidentified curved bacilli on gastric epithelium in active chronic gastritis. Lancet 1983; i: 1273-5.

11 Kerlin P, Tucker R, Phillips SF. Rapid intubation of the ileo-colonic region of man. Aust NZ J Med 1983; 13: 591-3.

12 Kerlin P, Zinsmeister A, Phillips S. Motor response to food of the ileum, proximal colon and distal colon of healthy humans. Gastroenterology 1983; 84: 762-70.

13 Camilleri M, Malagelada JR. Abnormal intestinal motility in diabetics with the gastroparesis syndrome. Eur J Clin Invest 1984; 14: 420-7.

14 Camilleri M, Brown ML, Malagelada J-R. Relationship between impaired gastric emptying and abnormal gastrointestinal motility. Gastroenterology 1986; 91: 94-9.

15 Jian R, Ducrot F, Piedeloup C, Mary JY, Najean Y, Bernier JJ. Measurement of gastric emptying in dyspeptic patients: effect of a new gastrokinetic agent (cisapride). Gut 1985; 26: 352-8.

16 Dubois A, Gross HA, Ebert MH, Castell DO. Altered gastric emptying and secretion in primary anorexia nervosa. Gastroenterology 1979; 77: 319-23.

17 McCallum RW, Berkowitz DM, Lerner E. Gastric emptying in patients with gastroesophageal reflux. Gastroenterology 1979; 77: 319-23.

18 Maddern GJ, Horowitz M, Jamieson GG, Chatterton BE, Collins BJ, Roberts-Thompson P. Abnormalities of esophageal and gastric emptying in progressive systemic sclerosis. Gastroenterology 1984; 87: 922-6.

19 Horowitz M, Maddox A, Maddern GJ, Wishart J, Collins PJ, Shearman DJC. Gastric and esophageal emptying in dystrophia myotonica. Gastroenterology 1987; 92: 570-7.

20 Mayer EA, Elashoff J, Hawkins R, Berquist W, Taylor I. Gastric emptying of mixed solid-liquid meal in patients with intestinal pseudoobstruction. Dig Dis $S_{c i}$ 1988; 33: 10-8

21 Stanghellini V, Malagelada JR. Gastric manometric abnormalities in patients with dyspeptic symptoms after fundoplication. Gut 1983; 24: 790-7.

22 Thompson DG, Richelson E, Malagelada JR. Perturbation of upper gastrointestinal function by cold stress. Gut 1983; 24: 277-83.

23 Stanghellini V, Malagelada JR, Zinsmeister A, Go VLW, Kao PC. Stress-induced gastrointestinal motor disturbances in man: possible humoral mechanisms. Gastroenterology 1983; 85: 83-91.

24 Tytgat GNJ, Langenburg ML, Rauws E, Rietra PJ. Campylobacter-like organisms in the human stomach [Abstract]. Gastroenterology 1985; 88: 1620.

25 Prakash C, Marshal B, Plankey R, Guerrant R, McCallum R. Gastric emptying of solids in patients with Campylobacter pylori gastritis [Abstract]. Am J Gastroenterol 1987; 82: 53. 